\title{
1. Introduction to Career Dynamics in a Global World
}

\section{Premarajan Raman Kadiyil, Anneleen Forrier and Michael B. Arthur}

An important question for researchers and practitioners in human resource management in general, and career development in particular, is this: are existing knowledge and practice developed in the West directly applicable to non-Western and particularly collectivistic societies? Or, to put it more specifically, does a predominant one-way influence of Western career concepts interfere with our understanding of careers in other parts of the world? There is good reason to ask these questions. Differences in national context, governance and culture have been widely shown to co-vary with people's career-related attitudes, orientations and behaviours across countries (Khapova, Briscoe and Dickmann, 2012; Tlaiss, 2014; Tsai et al., 2019).

In this book we take up the challenge to look beyond an emphasis on Western careers research. Specifically, we set out to compare ideas from a distinctly Eastern society, India, with related ideas from recognized Western societies. We hope that this comparison will not only serve careers research and practice across the two kinds of society, but also set an example for other international initiatives. We further hope that this will lead to a greater appreciation of career phenomena in a turbulent, substantially globalized economy.

We have also tried to position this book to encourage a conversation among and between career theorists and practitioners. In doing so we have created something very different from a typical comparative study, where matching research samples and methodologies are applied across geographies. Instead, we present eight pairs of chapters, with each pair involving one contribution from an Indian perspective and one from a Western perspective. Each pair also addresses a different topic, and each chapter offers a specific view of its subject within the topic area. In this way, we left greater scope for each authorship team to investigate and discuss phenomena of their own choosing within their adopted topic area. In every case, you are reading about something the authors consider to be important, and worth their time and energy in delivering their chapter to you. 
We have also chosen to provide a brief preview of each topic, suggesting some of the differences you may notice as you read along. However, they are only suggestions, intended to stimulate rather than restrict your further response to the material presented. We simply ask that you give yourself the opportunity to see deeper contrasts between the Indian and Western perspectives addressed, which in many cases carry over to other topics in the book. Our commitment to the adopted approach grew through successive stages in which we three editors spent time in India, conferred with other scholars and practitioners, developed our ideas, joined up with our publisher, and reached out to a wide range of both Indian and Western authors.

\section{HOW DID THE BOOK COME ABOUT?}

The inspiration for the book came from Premarajan Raman Kadiyil's invitation to Anneleen Forrier and Michael Arthur to visit the Centre for Human Resource Development, Xavier School of Management (XLRI), in Jamshedpur, India, in December 2018. During that visit, the three of us interacted with scholars from India and abroad and discussed their research. One of two kinds of research papers we saw focused on the distinctive circumstances of a country, in this case India, from which the paper originated. A second kind of papers were those such as those relating personality to career decision-making, that claimed broader applicability outside their country of origin.

We further noticed that it was the first kind of papers that promoted the liveliest conversation among the scholars we met. When we spoke with practitioners, they were also stimulated to talk about cultural differences underlying Indian and Western careers. As the three of us reflected on this, we asked ourselves what range of topics could we identify that would promote the kind of conversation and comparisons we were witnessing? At that point we reached out to Edward Elgar Publishing and went back and forth between the broader literature on careers and potential areas for comparison between India and the West. We ended up identifying four broad drivers giving rise to the evolution of careers today, and across which we might profitably look for contrasting insights. Those drivers are globalization, national culture, convergence/divergence and gender roles, each of which is discussed below.

\section{DRIVERS OF THE EVOLUTION OF CAREERS}

\section{Globalization}

Globalization has both an economic and a sociological meaning. An economic meaning comes from former Harvard Business School professor, Theodore Leavitt (1983), who argued that technology had 'proletarianized communica- 
tion, transport, and travel' and global markets had emerged 'on a previously unimagined scale of magnitude'. A sociological meaning from London School of Economics sociologist Anthony Giddens (1990, p. 64) refers to 'the intensification of worldwide social relations which link distant localities in such a way that local happenings are shaped by events occurring many miles away, and vice versa'. These voices of the West resonated with conversations already under way in India, where the minority government of Prime Minister P.V. Narasimha Rao and Finance Minister Dr Manmohan Singh introduced 'Liberalization, Privatization and Globalization' (LPG) reforms in 1991 to qualify for a much-needed loan from the International Monetary Fund (Wikipedia, 2019a).

Both economic and sociological globalization began to change Indian careers. The proletarianization of communication was encouraged by the release of the first commercial web browser in 1994 . Web browsing capability combined with email to enhance the coordination and movement of goods and the outsourcing of services. Further reforms were introduced in India from 1998 to 2004 (Wikipedia, 2019a). In the following year, Nandan Nilekani, CEO of the Indian software company Infosys, showed New York Times reporter Thomas L. Friedman his global video-conferencing room, and inspired Friedman to famously declare 'The world is flat' - in the sense that the business playing field had become levelled and that careers would never be the same (Friedman, 2005). India subsequently emerged as the second fastest growing economy in the world (Paul and Gupta, 2014) and perhaps the fastest growing economy in the world in 2018 based on GDP growth.

\section{Culture}

National culture reflects the underlying system of values, beliefs and preferences that are common among residents of a country (Hofstede, 2010) and is an important determinant of how people think and behave. Various studies have focused on cultural dimensions and variations as factors influencing career choice (Özbilgin, Küskü and Erdoğmuş, 2005; Shen et al., 2015). A popular although controversial view is that Asians are collectivistic, the self being identified with an in-group, while Westerners are individualistic, the self being distinct from the in-group (Noordin, Williams and Zimmer, 2002). Research suggests that parental expectations and adherence to traditional values have more influence on career development among the Indian population (Sandhu, 2014). National culture also provides a reference point for regional differences, where, for example, variability in cultural dimensions like individualism/collectivism may have an effect on people's career choices (Agarwala, 2008). 
A prominent cultural theme in India is spiritualism. In that, moksha (salvation) depends on an individual's karma (action or duty) based on his or her dharma (placement in the social order). In Gandhi's (1932) interpretation, work over time can be a means of self-realization. This contrasts sharply with Western views on enlightenment or rationalism (Wikipedia, 2019b). National cultures can also influence whether entrepreneurship becomes a career choice (Stephan and Uhlaner, 2010; Wennberg, Pathak and Autio, 2013) and can serve as a catalyst for globalization and its career consequences (Paul and Shrivastava, 2015). In addition, the existence of diverse national cultures challenges the common Western attribution of career behaviour to the inner person, rather than to cultural influences (Gibbons, Hughes and Woodside, 2015).

\section{Convergence/Divergence}

The overall idea of convergence is that globalization will blur differences between nation states. Convergence also has an economic and a sociological meaning. The economic meaning refers to the tendencies of societies 'to develop similarities in structures, processes and performances' (Kerr, 1983, p. 3) if the conditions of investment - such as a stable political system, dependable workers and relatively low wage rates - are favourable. With the introduction of the LPG reforms in 1991, India's greater openness to foreign investment, the availability of educated English language speakers, and pockets of expertise in technology and medicine have spurred convergence with the West. The sociological meaning comes from looking more deeply into political and social consequences of convergence. For example, sociologists raise concerns about increasing risks for employees. They also point to political and sociological arrangements to understand why convergence may not occur. For example, it may be argued that many Western countries have converged through their promotion of free trade arrangements over the last 40 years, allowing for the spread of manufacturing and service work around the globe. The shoes you wear, the cars you buy and the help to run your computer may now be sourced from anywhere around the globe (Encyclopedia.com, 2019).

Divergence occurs when nation states remain distinct and tailor changes to their own needs (Mills et al., 2008). That is where a nation's political history, different institutions and distinct values and norms come into play. There are concerns, though, that the apparent growth of political extremism, recent US scepticism toward free trade, and greater international tensions over global warming will herald an overemphasis on divergence (Mills et al., 2008). We need to better understand global career dynamics to better understand how 
individual careers will both influence and be influenced by larger geopolitical forces.

\section{Gender Roles}

Gender role expectations and gender-based socializations across cultures are another set of key variables that can influence the career journey of individuals. The World Economic Forum's Gender Gap Economic Participation and Opportunity Subindex reports the following data from the three countries represented by the editors of this book: India ranked 139 in 2013, 136 in 2015 and 142 in 2018 (out of 149 countries). In contrast, the US went from 43 (2012) to 53 (2015) to 52 (2018) and Belgium went from 34 to 37 to 49 (World Bank, 2019). In terms of political representation, women stand at 11 per cent of the total parliamentary representatives in India, 24 per cent in the US and 40 per cent in Belgium (Inter-Parliamentary Union, 2019). The percentage of female CEOs in India is 3 per cent (Verma and Basu, 2019), around 5 per cent in US leading companies (Desilver, 2018) and 10 per cent in Belgium (Page Group, 2019). The key question, of course, is what is holding women back?

The limited levels of women's participation in executive and political life prevail despite the widespread attention the subject has received over the past 30 years (Frear et al., 2019). Much of the literature has focused on the challenges that women face in entering the workforce generally, and particularly the professions, as well as the difficulties they face in advancing to higher levels within organizations or professions (Triana et al., 2019; Wille et al., 2018). It also seems clear that women continue to face stereotyping, biases in performance appraisal, promotion and salary and difficult work-life trade-offs (Cohn, 2019). A further key question is whether a combination of cultural and family circumstances leads to women being 'pushed out' of successful careers (Kossek, Su and Wu, 2017).

\section{TOPICS AND CHAPTERS}

With the above four drivers in mind, we built on what we had learned and made a list of topics that we anticipated could respond to the energy we had witnessed, and signed on with Edward Elgar Publishing. As noted earlier, we came up with the idea of explicitly pairing Indian and Western chapters, reached out to scholars we knew about and searched widely for further scholars with expertise on the topics selected. As a result, we came up with the eight topics and 16 authorship teams represented in this book. Upon receiving draft chapters, we encouraged each authorship team to consider and cite the work of its paired chapter. The eight topics, with associated chapters and author teams, are indicated below. 


\section{Self and Career}

This topic responds to the globalization and cultural drivers identified above. Anupama Kondayya and Srinivas Ekkirala in Chapter 2, 'An incongruence-driven approach to careers: insights from Ayurveda', present a distinctive approach to person-environment fit derived from an ancient Indian science. In a volatile, uncertain, complex and ambiguous world, individuals are advised to respond through adaptability, versatility and flexibility. Specifically, career variety is highlighted as a way to develop adaptability. In contrast, Marijke Verbruggen in Chapter 3 on 'Self-awareness in career development: meaning, importance and malleability', explores Western literature on self-awareness, asserting that people ought to emphasize who they already are, and what strengths they already have. However, her ideas about malleability as an important career competence connect back to the Ayurvedic approach.

\section{Social Entrepreneurship as a Career Choice}

This topic also responds to both the globalization and cultural drivers. Preeti Tiwari, Anil K. Bhat and Jyoti Tikoria provide Chapter 4, 'A field research of nascent social entrepreneurs' intention formation', and look at how social entrepreneurial education, social entrepreneurial self-efficacy, empathy and moral obligation in India influence social entrepreneurs' intention toward launching a business. Mary Conway Dato-on, Sharmistha Banerjee and Yasmin Mesbah in Chapter 5, 'Individual factors in predicting and encouraging social entrepreneurship as a career choice', offer a similar study from the US. Their work finds common ground with their Indian counterparts on social entrepreneurial education and social entrepreneurial self-efficacy. However, they find separate ground for empathy and moral obligation, which show no influence over their subjects' entrepreneurial intentions.

\section{Stepping Off the Career Ladder}

This topic responds to both cultural and gender roles drivers underlying decisions to either step off or stay on a career ladder. Sumita Datta and Snehal Shah in Chapter 6, 'Satisficing career choices of Indian women managers', observe the interaction with changing family structures and career choices of women. A common outcome is that women 'satisfice' and adjust their careers downwards to adapt to family responsibilities. Angela Stephanie Mazzetti's chapter, Chapter 7, 'Stepping off the career ladder: exploring the impact of career shocks on women's career decisions in the UK', investigates career shocks that women experience. Positive shocks can turn negative, and vice versa, and negative shocks can create downward spirals of resource loss. However, the 
development of 'resource-enhancing environments' can benefit both women and organizations.

\section{MBA Careers Across the Globe}

This topic responds primarily to the drivers, globalization and convergence/ divergence. Vivek G. Nair and Leena Chatterjee contribute Chapter 8, 'Economic structural changes and subjective career success of MBAs in India'. They study two groups of MBA students largely educated either before or after the liberalization of the Indian economy in the early 1990s and show how the two groups differ in their perceptions of career success. Elizabeth Houldsworth, Chris Brewster and Richard McBain deliver Chapter 9, 'How an MBA contributes to the unfolding of careers: a comparative analysis'. They look at the outcomes for alumni of the same Western MBA programme offered in different parts of the world. Context clearly matters a great deal in the career development of these MBA alumni.

\section{Breaking and Re-entry}

Our next topic responds directly to the gender roles driver, and also explores how different cultures reinforce those roles. Pavni Kaushiva and Chetan Joshi's chapter, Chapter 10, is titled 'Women's careers: starting a new chapter post career break'. They describe an experimental study that revealed a pattern of neosexism over whether to hire a woman returning to work after a career break. Anna Katharina Bader and John Blenkinsopp counter with Chapter 11, 'Can we release the brake on the career re-entry of mothers? A UK perspective'. Their chapter also focuses on women returning to work after a career break, who face challenges despite the robust legal framework that exists to support them. The combination of chapters points to the continuation of privileged career opportunities for men in both situations.

\section{Academic Careers}

Our next topic also focuses on the three drivers, globalization, culture and convergence/divergence. Ravishankar Venkata Kommu and Amit Dhiman bring us Chapter 12, 'The changing nature of academic careers in management education in India', and apply the legendary French sociologist Pierre Bourdieu's ideas to the 'career field' of Indian academics in management education. The authors describe how 'winds of change' stemming from globalization, neoliberalism and managerialism have become embedded within the Indian context. Yehuda Baruch in Chapter 13 discusses 'The changing nature of academic careers in management education in Western societies'. He 
takes an ecological view that sees individuals, institutions and social entities interdependently influencing scholars' emergent career patterns. He observes a dominant Anglo-Saxon model across the global management education arena, with forces of supply and demand shaping and being shaped by academic career paths.

\section{Careers in IT}

Our next topic highlights globalization and an industry that has thrived in India since the introduction of economic reforms. Gunjan Tomer and Pawan Budhwar's chapter, Chapter 14, is titled 'Flying high in the turbulent skies: managing careers in the Indian IT industry'. They describe a persistent tension between the IT worker's needs for challenging work and career development and the employer's need to manage resources and sustain competitive advantage. Sara Haviland and Jennifer Craft Morgan respond with Chapter 15, 'Risk allocation, employer dependence and the welfare state: an investigation of IT workers in the US and Canada'. They report how IT workers' perceptions of risk in the US and Canada are affected by the 'welfare regime' they live in, and where US workers look to maintain employer-dependent benefits more than their Canadian counterparts.

\section{Opting Out or Staying In}

Our final topic engages with all four drivers: globalization, culture, convergence/divergence and gender roles. Tania Saritova Rath and Mousumi Padhi bring us Chapter 16, 'Integrating care work for sustainable careers of women: an Indian perspective', and highlight a sharp decline in labour force participation of Indian women with children. A focus on highly educated women finds them opting out of the workforce, seeing unpaid caregiving work as more important than paid work. Margie J. Elley-Brown closes with Chapter 17, titled 'Leaning in: why some women are challenging the opt-out model', and focuses on New Zealand women's career decisions to stay in the workforce. The educators she studied made decisions in consultation with their partners, including decisions where the women took a 'front seat' in dual-career partnerships.

$$
* * *
$$

We have had our say. We hope you are interested to read on from here and engage with the topics and chapters as we have suggested. We hope this book leads you - wherever you may live, and whether scholar or practitioner - to a deeper awareness of global career dynamics. We further hope that such 
awareness will lead to more effective conversation and greatly improved practice. Let the work begin!

\section{REFERENCES}

Agarwala, T. (2008), 'Factors influencing career choice of management students in India', Career Development International, 13(4), 362-76.

Cohn, S. (2019), Race, Gender, and Discrimination at Work, New York: Routledge.

Desilver, D. (2018), 'Women scarce at top of U.S. business - and in the jobs that lead there', Pewresearch.org, 20 April 2018, accessed 14 October 2019 at https://www .pewresearch.org/fact-tank/2018/04/30/women-scarce-at-top-of-u-s-business-and-in -the-jobs-that-lead-there/.

Encyclopedia.com (2019), 'Convergence theories', accessed 14 October 2019 at https://www.encyclopedia.com/social-sciences/encyclopedias-almanacs-transcripts -and-maps/convergence-theories

Frear, K.A., S.C. Paustian-Underdahl, E.D. Heggestad and L.S. Walker (2019), 'Gender and career success: a typology and analysis of dual paradigms', Journal of Organizational Behavior, 40(4), 400-416.

Friedman, T.L. (2005), 'It's a flat world, after all', The New York Times Magazine, 3 April 2005, accessed 14 October 2019 at https://www.nytimes.com/2005/04/03/ magazine/its-a-flat-world-after-all.html.

Gandhi, M.K. (1932), 'Working and thinking', in Collected Works of Mahatma Gandhi, Vol. 57, pp. 22-3, accessed 28 January 2020 at https://www.gandhiashramsevagram .org/gandhi-literature/collected-works-of-mahatma-gandhi-volume-1-to-98.php.

Gibbons, M., M.A. Hughes and M. Woodside (2015), 'Exploring the influence of culture on career through the career-in-culture interview', Adultspan, 14(2), 77-89.

Giddens, A. (1990), The Consequences of Modernity, Cambridge, UK: Polity Press.

Hofstede, G. (2010), 'The GLOBE debate, back to relevance', Journal of International Business Studies, 41(8), 1331-46.

Inter-Parliamentary Union (2019), 'Women in national parliaments', accessed 14 October 2019 at http://archive.ipu.org/wmn-e/classif.htm.

Kerr, C. (1983), The Future of Industrial Societies: Convergence or Continuing Diversity?, Cambridge, MA: Harvard University Press.

Khapova, S.N., J.P. Briscoe and M. Dickmann (2012), 'Careers in cross-cultural perspective', in J.P. Briscoe, D.T. Hall and W. Mayrhofer (eds), Careers Around the World: Individual and Contextual Perspectives, New York: Routledge, pp. 15-38.

Kossek, E.E., R. Su and L. Wu (2017), “"Opting out" or "pushed out”? Integrating perspectives on women's career equality for gender inclusion and interventions', Journal of Management, 43(1), 228-54.

Leavitt, T. (1983), 'The globalization of markets', Harvard Business Review, May, accessed 14 October 2019 at https://hbr.org/1983/05/the-globalization-of-markets.

Mills, M., H.P. Blossfeld, S. Buchholz, D. Höfacker, F. Bernardi and H. Hofmeister (2008), 'Converging divergences? An international comparison of the impact of globalization on industrial relations and employment careers', International Sociology, 23(4), 561-95.

Noordin, F., T. Williams and C. Zimmer (2002), 'Career commitment in collectivist and individualist cultures: a comparative study', The International Journal of Human Resource Management, 13(1), 35-54. 
Özbilgin, M., F. Küskü and N. Erdoğmuş (2005), 'Explaining influences on career "choice": the case of MBA students in comparative perspective', The International Journal of Human Resource Management, 16(11), 2000-2028.

Page Group (2019), 'The position of women in companies and female leadership in Belgium' [media release], accessed 14 October 2019 at https://www.michaelpage .be/sites/michaelpage.be/files/Media\%20release_gendergap_EN.pdf.

Paul, J. and P. Gupta (2014), 'Process and intensity of internationalization of IT firms evidence from India', International Business Review, 23(3), 594-603.

Paul, J. and A. Shrivastava (2015), 'Comparing entrepreneurial communities: theory and evidence from a cross-country study in Asia', Journal of Enterprising Communities: People and Places in the Global Economy, 9(3), 206-20.

Sandhu, G. (2014), 'The influence of family and cultural values on the career development of Asian Americans', Doctor of Philosophy (Counselling Psychology) dissertation, August 2014, accessed 14 October 2019 at https://digital.library.unt.edu/ark:/ 67531/metadc799461/.

Shen, Y., B. Demel, J. Unite, J.P. Briscoe, D.T. Hall and K. Chudzikowski (2015), 'Career success across 11 countries: implications for international human resource management', The International Journal of Human Resource Management, 26(13), 1753-78.

Stephan, U. and L. Uhlaner (2010), 'Performance based vs. social supportive culture: a cross national study of descriptive norms and entrepreneurship', Journal of International Business Studies, 41, 1347-64.

Tlaiss, H.A. (2014), 'Between the traditional and the contemporary: careers of women managers from a developing Middle Eastern country perspective', The International Journal of Human Resource Management, 25(20), 2858-80.

Triana, M.D.C., M. Jayasinghe, J.R. Pieper, D.M. Delgado and M. Li (2019), 'Perceived workplace gender discrimination and employee consequences: a meta-analysis and complementary studies considering country context', Journal of Management, 45(6), 2419-47.

Tsai, C.-J., C. Carr, K. Qiao and S. Supprakit (2019), 'Modes of cross-cultural leadership adjustment: adapting leadership to meet local conditions and/or changing followers to match personal requirements?', The International Journal of Human Resource Management, 30(9), 1477-504.

Verma, P. and S.D. Basu (2019), 'At only 3\%, corporate India is still struggling to bring women to the top', Economic Times, 27 March 2019, accessed 14 October 2019 at https://economictimes.indiatimes.com/news/company/corporate-trends/at -only-3-corporate-india-is-still-struggling-to-bring-women-to-the-top/articleshow/ 68589499.cms.

Wennberg, K., S. Pathak and E. Autio (2013), 'How culture moulds the effects of self-efficacy and fear of failure on entrepreneurship', Entrepreneurship \& Regional Development, 25(9-10), 756-80.

Wikipedia (2019a), 'Economic liberalisation in India', accessed 14 October 2019 at https://wikipedia.org/wiki/Economic_liberalisation_in_India.

Wikipedia (2019b), 'Rationalism', accessed 14 October 2019 at https://en.m.wikipedia .org/wiki/Rationalism.

Wille, B., B.M. Wiernik, J. Vergauwe, A. Vrijdags and N. Trbovic (2018), 'Personality characteristics of male and female executives: distinct pathways to success?', Journal of Vocational Behavior, 106, 220-35.

World Bank (2019), 'Global Gender Gap Economic Participation and Opportunity Subindex', accessed 14 October 2019 at https://tcdata360.worldbank.org/indicators/. 